\title{
Effect of Mechanical Ventilation Mode Type on Prioperative Blood Loss in Patients Undergoing Posterior Lumbar Inter body Fusion Surgery: A Randomized Controlled Trial
}

\author{
Manoochehr Salimian ( $\nabla$ drmsr_44@yahoo.com ) \\ Kashan University of Medical Sciences \\ Mohammad Hajijafari \\ Kashan University of Medical Sciences \\ Esmaeil Fakharian \\ Kashan University of Medical Sciences \\ Meghdad Rahati \\ Kashan University of Medical Sciences
}

\section{Research Article}

Keywords: Pressure-controlled ventilation, Volume-controlled ventilation, Posterior spinal fixation surgery, Randomized Controlled Trial, Surgery, Bleeding

Posted Date: October 13th, 2021

DOI: https://doi.org/10.21203/rs.3.rs-754157/v1

License: (c) (i) This work is licensed under a Creative Commons Attribution 4.0 International License.

Read Full License 


\section{Abstract \\ Background}

this study has examined modes of mechanical ventilation, pressure or volume-controlled ventilation (PCV or VCV) on intra- and post-operative surgical bleeding in posterior lumbar inter body fusion (PLIF) surgery

\section{Methods}

This research was a randomized, single-blinded, and parallel study, that 78 patients were selected. They mechanically ventilated using either PCV or VCV in PLIF surgery. In this regard, a permuted block randomization was used with a computer-generated list. After induction of anesthesia in supine position, the hemodynamic and respiratory parameters were measured

\section{Results}

The mean bleeding was $431.281 \pm 361.04 c c$ in the PCV group and $465.26 \pm 338.16 \mathrm{cc}$ in the VCV group $(p=0.669)$. Moreover, blood transfusion rates in the PCV and VCV groups were $0.40 \pm 0.74$ and $0.43 \pm 78$ 0.78 pack cell $(p=0.836)$, respectively. Notably, surgeon satisfaction was more observed in the PCV group $(82.1 \%$ vs. $74.4 \%, p=0.548)$. In addition, the other variables were similar in these two groups.

\section{Conclusions}

The mean bleeding volume was higher in the VCV group compared to the PCV group; however, no significant difference was observed between these two groups. Hemoglobin levels in the patients included before and after surgery showed that the two groups were in a similar condition.

\section{Background}

It was indicated that posterior spinal fixation surgery is often associated with heavy bleeding that sometimes requires a blood transfusion or blood product $(1,2)$ The need for blood transfusion in spinal fusion surgeries without any implantation of the device was reported in $70 \%$ of the cases and in case of using the device, it was up to $50 \%$ of the cases. Additionally, the estimated bleeding rates have been reported in studies to be between 80 and $3100 \mathrm{cc} .(3,4,5,6,7$, and 8$)$

In spinal deformity correction surgeries performed using posterior reversal methods, the amount of bleeding has been reported to be from 1 to 3 liters $(9,10,11,12,13$ and 14). Accordingly, there are similar reports in interior correction $(15,16)$. Reduction of intraoperative bleeding is important for maintaining hemodynamic stability and the desirability of the surgical field. On the other hand, it was found that the convenience of the surgeon reduces the duration of the operation, which is accompanied with a reduction 
in the amount of bleeding $(2,17)$. Moreover, reducing bleeding reduces the need for blood transfusions and blood products, which consequently decreases the risks of hemolytic and non-hemolytic complications, lung damage, viral and bacterial infections, and hypothermia and coagulation disorders caused by blood transfusions (2, 18 and 19$)$.

The techniques used to reduce intraoperative bleeding and the suitability of the surgical field are divided into two groups as follows: 1- Reduction of bleeding by reducing intravenous blood flow such as the controlled hypotension and local vascular contraction, and 2- Accelerating and stabilizing coagulation using chemical and biological agents such as desmopressin, aprotinin, and tranexamic acid; estrogen; and bone wax. Correspondingly, these techniques have been widely studied as contradictory results, and finally many contradictory findings have been obtained $(19,20,21,22,23$ and 24).

Mechanical ventilation increases the pressure inside the chest, reduces vascular return, and increases venous pressure, which finally increase bleeding. Few studies in this regard have shown that reducing intrathoracic pressure in mechanical ventilation by maintaining spontaneous respiration over the controlled respiration can be effective on reducing site bleeding (10). On the other hand, changes in $\mathrm{CO} 2$ can affect the central arteries and the pressure inside the skull can also affect the amount of bleeding in the fixation of the spine $(10,25,26$ and 27$)$.

Due to the limited studies conducted on the effect of respiratory ventilation on the reduction of intraoperative bleeding as well as the positive effects that can have on the outcome of patients, which lead to the reduced loss and transfusion of blood and blood products during spinal surgery, in the present study, the effects of two types of Mechanical ventilation including volumetric ventilation (VCV) and compression ventilation (PCV) were evaluated on intraoperative surgical bleeding in patients undergoing spinal surgery.

\section{Methods}

\section{Ethics and patients}

This study protocol was approved by the Ethics committee of Kashan University of Medical Sciences (Ghotb-e-Ravandi Blvd, 5th Km, Kashan Road, 8715988141, Kashan, I. R. Iran- Postal code: 8715988141). All methods were carried out in accordance with relevant guidelines and regulations and with CONSORT recommendations. The study was registered in Kashan University of Medical Sciences ( The link for the study registry: https://irct.ir/user/trial/24834/view, Trial Id: 24834, IRCT Id: IRCT2016122731611N1, Registration date: 18/03/2017).

In this prospective, randomized, parallel and one-way blinded clinical trial, 78 patients with ASA class 1 and 2, aged between 18 and 75 years old, who were candidates for posterior spinal fixation surgery, were included and then randomly divided into two groups of 39 subjects after obtaining the written informed consent. 
This study was prospective, randomized, and parallel (allocation ratio $=1: 1$ ).

For the participants' allocation, the permuted block randomization was used by applying a computergenerated list of random numbers and using sealed envelopes. Although surgeons and nurses who were involved in patient care, were aware of the study they were blinded to the details of the study's protocol. The surgical procedure was performed by one surgeon and a single surgical team using the same method.

The permuted block randomization was used for the participants' allocation (allocation ratio=1:1). in this regard used random numbers that extracted from computer-generated list and sealed envelopes.

\section{Anesthetic protocol:}

Anesthesia was induced and then maintained by the attending anesthesiologist, who managed anesthesia using a standard regimen in the study protocol; however, he was blinded to the details of the study protocol. After establishing routine patient monitoring (Heart rate, noninvasive blood pressure, pulse oximetry, and end tidal CO2), anesthesia was induced with an intravenous premedication of $2 \mu \mathrm{g} / \mathrm{kg}$ fentanyl, $0.03 \mathrm{mg} / \mathrm{kg}$ midazolame, $5 \mathrm{mg} / \mathrm{kg}$ sodium thiopental, and $0.5 \mathrm{mg} / \mathrm{kg}$ atracurium. Endotracheal tube with a suitable size, a high-volume, and a low-pressure cuff was inserted for the patients.

Anesthesia was maintained with infusion of propofol $100-200 \mathrm{Mic} / \mathrm{Kg} / \mathrm{min}$ as well as $30 / 70 \%$ of $02 / \mathrm{N} 20$ mixture to maintain $70 \mathrm{mmHg}$ of MAP, if any additional drug was necessary to maintain $70 \mathrm{~mm} \mathrm{Hg}$ of MAP labetalol infused. In the PCV group, mechanical ventilation begun with $P I P=15 \mathrm{mmHg}, \mathrm{RR}=12 / \mathrm{min}$, $I / E=1 / 2$, and $P E E P=0$ and then the PIP was adjusted to achieve a tidal volume that was calculated as the ideal body weight (50 [female: 45.5$]+0.91$ [height -152.4$]) \times 7 \mathrm{ml}$. In addition, the respiratory rate was controlled. Using the end-tidal carbon dioxide pressure (ETCO2) ranged from 35 to $40 \mathrm{mmHg}$. In the VCV group, $\mathrm{TV}=7 \mathrm{ml} / \mathrm{IBW}$ and RR, I/E, and PEEP were chosen as one group. Afterward, anesthesia was reversed with $0.04 \mathrm{mg} / \mathrm{Kg}$ neostigmine and $0.02 \mathrm{mg} / \mathrm{Kg}$ atropine.

Measurements hemodynamic changes BP, HR, MAP, amount of blood loss, and transfusion were recorded intera and post-operative duration of surgery was recorded as well.

In this study, the amount of bleeding was calculated based on the volume of blood lost in the suction, the number of completely impregnated gases ( $4 \times 4 \mathrm{~cm}, 15 \mathrm{cc}$ each), large amount of completely impregnated blood ( $30 \times 30 \mathrm{~cm}$ per $50 \mathrm{cc}$ ), and the amount of blood in the hemovac drain of the patients and then registered until the end of the operation.

Additionally, the amount of blood and blood products injected during the operation along with blood pressure and heart rate were recorded before the induction, immediately after the intubation, after being in the prone position, during the operation every 15 minutes, at the end of the operation, after being in the supine position, and after endotracheal tube exit and recovery time.

Afterward, postoperative hemoglobin levels were checked after the arrival to general ward. 
Surgeon's satisfaction from the field of surgery was also questioned and recorded as good, moderate, and weak, which were stated based on the volume of bleeding, the bleeding conditions of the operation field, and the surgeon's personal opinion.

All the obtained data were measured and recorded by one trained observer who was not aware of each group. All the patients operated by one surgeon who was not informed of the method of ventilation.

\section{Statistical analysis}

The findings were described with central and environmental indicators and then displayed with the related tables and graphs. The findings analyzed using Kolmogorov-Smirnov test, parametric t-test and Fisher's exact test and also with Chi-square tests. SPSS-16 software was used to analyze data.

In this study, details of the protocol were blinded for surgeons and nurses. A surgeon was applying surgical procedure and a single surgical team used the same method

\section{Patient's inclusion criteria}

The patient's inclusion criteria were as follows:

1. Patients with ASA class 1 or 2 ,

2. Ages between 18 and 75 years old,

3. Patient consent to enter the study

The patient's exclusion criteria were as follows:

1. Respiratory diseases like Asthma, and chronic obstructive pulmonary diseases.

2. Severe heart diseases such as heart failure, myocardial infarction, and valvular diseases.

3. Coagulation diseases or anticoagulation drug consumption.

4. Severe hemodynamic instability preoperative, And

5. History of any previous lumbar surgery

This study was done from 2017 to 2019 at the university teaching hospital and gave the approval of the Institutional Review (95051) of Kashan University of medical science. (Ethical code IR.KAUMS.REC.1395.50)

\section{Result}

In this study, 78 patients who were candidates for posterior spinal fixation surgery were studied in the two groups of volume control ventilation and pressure ventilation in terms of the amount of bleeding caused by the operation. The variables of sex, age, height, weight, and body mass index (BMI) of the studied patients showed that these were not significantly different between these two groups (Table 1). 
According to Table 1, 38.5\% of the patients in the VCV group and $41.0 \%$ of the patients in the PCV group were Male, and $61.5 \%$ of the patients in the VCV group and $59 \%$ of the patients in the PCV group were Female. The difference between two group was not statistically significant $(p=0.82)$. The mean age of the patients enrolled in the VCV group was $42.41 \pm 10.45$ years old and in the PCV group was $43.77 \pm 11.38$ years old $(p=0.53)$. The mean height of the patients enrolled in the VCV group was $1.65 \pm .9$ meter and in the PCV group was $1.66 \pm .1$ meter $(p=0.54)$. The mean weight of the patients enrolled in the VCV group was $76.11 \pm 11.47 \mathrm{~kg}$ and in the PCV group was $78.77 \pm 19.71 \mathrm{~kg}(\mathrm{p}=0.13)$. The mean BMI of the patients enrolled in the VCV group was $27.92 \pm 4.89$ and in the PCV group was $28.42 \pm 7.10(p=0.93)$.

The mean bleeding volume in the studied groups was shown in table 2. the volume of bleeding due to surgery in the VCV group was $465.26 \mathrm{cc}$ and in the PCV group, it was $431.28 \mathrm{cc}$; however, no significant difference was observed between these two groups $(p=0.67)$ (Table 2$)$.

Most of the patients in both treatment groups required no blood transfusions. In the VCV Group 17.9\% and in the PCV Group 15\%, although the patients needed two pack cells of blood. The difference between these two groups was not statistically significant $(p=1)$ (Table 3$)$.

Surgeon evaluation of the surgical field in $74.4 \%$ of the patients in the VCV group and $82.1 \%$ of the patients in PCV Group has shown good results $(p=0.58)$ (Table 4).

The frequency of the need for antihypertensive drugs during surgery in the VCV group was $10.3 \%$ and in the PCV Group was $5.1 \%$, which were not statistically significant $(p=0.22)$ (Table 5$)$.

Comparison of hemoglobin levels of patients before and after surgery showed that these two groups were in a similar condition. After removing the effects of age, sex, body mass index, duration of operation, and basal hemoglobin no changes were observed in hemoglobin levels between the two groups. (Table $6)$.

\section{Discussion}

This study reported that the mean volume of bleeding due to surgery in the ventilation group with volume control was $465.26 \mathrm{cc}$, and in the ventilation group with pressure control, it was $431.28 \mathrm{cc}$, but no significant difference was observed between these two groups $(p=0.67)$. The results of the Kang's study showed that the rate of intraoperative bleeding in the PCV group was lower than the VCV group in patients undergoing similar surgery (253 and $382 \mathrm{ml}$ ), respectively (28). However, in the study of Le Guen and et al (2019) that examined the effect of mechanical ventilation modality, showed no bleeding in trans sphenoidal pituitary surgery (29). Accordingly, the difference can also be related to the impact of some other factors such as the length of surgery and the number of surfaces that should be operated. The average duration of surgery in Kang's study was 156 minutes and in the present study, it was 146 minutes. In addition, another variable was the age of the include patients that was less than 46 years old in both groups, but in the Kang's study, it was more than 64 years old. It was indicated that age alone with 
cardiovascular changes can have a great impact on the amount of bleeding directly or indirectly by exacerbating the other factors.

The Guen's study challenged the possible effect of ventilation type as well as the increased intrathoracic pressure on venous return in positive pressure ventilation and as a result rejected its clinical effect, which is consistent with the results of the present study. However, the sitting position could still be considered as a contributing factor in these differences.

Comparison of hemoglobin levels of the patients before and after surgery showed that the two groups were in a similar condition. This finding is similar with the findings of other studies $(11,18,19$ and 27$)$. Although the amount of intraoperative bleeding was different between these two groups, the measured hemoglobin and hematocrit were not significantly different between them at any time. Therefore, this indicates that hemoglobin and hematocrit are not good indicators of intraoperative bleeding, which can be due to various causes like fluid shifts. Furthermore, there was no difference in the amounts of postoperative bleeding at 24 and 72 hours between the two groups.

In the present study, most of the patients in both treatment groups required no blood transfusions. Notably, in the ventilation group with volume control of $74.4 \%$ and in the ventilation group with pressure control of $75 \%$, the difference between the two groups was not statistically significant $(p=1)$.

The surgeon evaluated the surgical field in $74.4 \%$ of the patients in the ventilation group with volume control and $82.1 \%$ of the patients in the ventilation group with a good pressure control $(p=0.58)$. This finding is in agreement with a similar study (27).

Due to the limited studies performed similar to our study, the comparison of most of the results of this study with other studies was limited.

\section{Conclusion}

The mean volume of bleeding due to surgery was higher in the volume-controlled ventilation group compared to the pressure-controlled ventilation group, but no significant difference was observed between these two groups. Due to the inconsistencies in few studies available, the role of ventilation type in the rate of bleeding cannot be confirmed as an independent variable, so it needs further investigations.

\section{Abbreviations}

PCV: Pressure controlled ventilation

VCV: Volume controlled ventilation

PLIF: Posterior lumbar inter body fusion

\section{Declarations}


Acknowledgements

This study was done after obtaining the approval of the Institutional Review (95051) of Kashan University of medical science.

\section{Authors' contributions}

Salimian Manoochehr collected and analyzed the data and wrote the paper. Hajijafari Mohammad analyzed the data. Fakharian Esmaeil helped with the clinical anaesthesia management. Meghdad Rahati helped with the study design and revision of the paper. All authors read and approved the final manuscript.

\section{Funding}

This study has no funding.

\section{Availability of data and materials}

The datasets used and analyzed during the current study are available from the corresponding author on reasonable request. The corresponding author: Salimian Manoochehr, Email: drmsr_44@yahoo.com.

\section{Ethics approval and consent to participate}

This study was approved by the Ethics Committee of the Kashan University of Medical Sciences.

Address: Kashan University of Medical Sciences, Ghotb-e-Ravandi Blvd, 5th Km, Kashan Road, 8715988141, Kashan, I. R. Iran- Postal code: 8715988141

Ethics committee reference number: IR.KAUMS.REC.1395.50.

\section{Consent for publication}

Written informed consents were obtained from all participants' parents. All experiment procedures (consisted of invasive manipulation) and data collection were conducted with prior informed consent.

\section{Competing interests}

All authors declare that they have no conflicts of interest.

\section{Author details}

1. Salimian Manoochehr: Kashan University of Medical Sciences, Kashan, I.R. Irandrmsr_44@yahoo.com-ORCID: https://orcid.org/0000-0002-0545-4234

2. Hajijafari Mohammad: Kashan University of Medical Sciences, Kashan, I.R. Irandr_hajijafari@yahoo.com-ORCID:https://orcid.org/0000-0002-0831-5707 
3. Fakharian Esmaeil: Kashan University of Medical Sciences, Kashan, I.R. Iran-e.fakharian@gmail.comORCID:https://orcid.org/0000-0003-0115-8398

4. Meghdad Rahati: Kashan University of Medical Sciences, Kashan, I.R. Iran

-mrahati90@yahoo.om-ORCID:https://orcid.org/0000-0002-1208-063X

Corresponding Author: Salimian Manoochehr: Kashan University of Medical Sciences, Kashan,

I.R.Iran-drmsr_44@yahoo.com-phone: +989136311275

\section{References}

1. Cole JW, Murray DJ, Snider RJ, Bassett GS, Bridwell KH, Lenke LG. Aprotinin reduces blood loss during spinal surgery in children. Spine. 2003;28(21):2482-5. DOI:

10.1097/01.brs.0000090835.45437.7f

2. Szpalski M, Gunzburg R, Sztern B. An overview of blood-sparing techniques used in spine surgery during the perioperative period. Eur Spine J. 2004;13 Suppl 1: S18-27. PMID: 15480823

3. Nahtomi-Shick O, Kostuik JP, Winters BD, Breder CD, Sieber AN, Sieber FE. Does intraoperative fluid management in spine surgery predict intensive care unit length of stay? J Clin Anesth. 2001 May;13(3):208-12. DOI: 10.1016/s0952-8180(01)00244-6

4. Tobias JD. Sevoflurane for controlled hypotension during spinal surgery: preliminary experience in five adolescents. Paediatr Anaesth 1998; 8: 167-70. DOI: 10.1046/j.1460-9592.1998.00700.x

5. Serena S. Hu Blood loss in adult spinal surgeryEur Spine J. 2004 Oct; 13(Suppl 1): S3-S5.Published online 2004 Jun 10. DOI: 10.1007/s00586-004-0753-x

6. Swank S, Lonstein JE, Moe JH, Winter RB, Bradford DS Surgical treatment of adult scoliosis. A review of two hundred and twenty-two cases. J Bone Joint Surg Am. 1981 Feb;63(2):268-87. PMID: 6450768

7. 7-Boachie-Adjei O, Bradford D. The Cotrel-Dubousset system--results in spinal reconstruction. Early experience in 47 patients.Spine (Phila Pa 1976). 1991 Oct;16(10):1155-60. DOI: 10.1097/00007632199110000-00005

8. Modig J, Karlstrom G. Intra and post-operative blood loss and hemodynamics in total hip replacement when performed under lumbar epidural versus general anaesthesia. Eur J Anaesthesiol, 1987; 4: 345-355. PMID: 3322824

9. Boachie-Adjei O, Do T, Rawlins BA. Partial lumbosacral kyphosis reduction, decompression, and posterior lumbosacral transfixation in high-grade isthmic spondylolisthesis: clinical and radiographic results in six patients. Spine (Phila Pa 1976). 2002 Mar 15;27(6):E161-8. DOI: 10.1097/00007632200203150-00019

10. Prys-Roberts C. Effects of mechanical ventilation on the heart and pulmonary circulation. SNPM,1978; T.3: 1919-1926.

11. Taghipour Anvari Z, Afshar-Fereydouniyan N, Imani F, Sakhaei M, Alijani B, Mohseni M. Effect of clonidine premedication on blood loss in spine surgery. Anesth Pain Med. 2012;1(4):252-6. DOI: 
10.5812/aapm.2197

12. Modig J. Regional anesthesia and blood loss. Acta Anesthesiol Scand, 1988; 32 (suppl 89): 44-48. DOI: 10.1111/j.1399-6576.1988.tb02842.x

13. Boachie-Adjei O, Do T, Rawlins BA Partial lumbosacral kyphosis reduction, decompression, and posterior lumbosacral transfixation in high-grade isthmic spondylolisthesis: clinical and radiographic results in six patients. Spine (Phila Pa 1976). 2002 Mar 15;27(6):E161-8. DOI: 10.1097/00007632200203150-00019

14. Allen BL Jr, Ferguson RL. The Galveston experience with L-rod instrumentation for adolescent idiopathic scoliosis. Clin Orthop Relat Res. 1988 Apr;(229):59-69. PMID: 3280204

15. Kaneda K, Fujiya N, Satoh S. Results with Zielke instrumentation for idiopathic thoracolumbar and lumbar scoliosis.Clin Orthop Relat Res. 1986 Apr;(205):195-203. PMID: 3698377

16. Ani N1, Keppler L, Biscup RS, Steffee ADAbstract. Reduction of high-grade slips (grades III-V) with VSP instrumentation.Report of a series of 41 cases.Spine (Phila Pa 1976). 1991 Jun;16(6 Suppl):S302-10. DOI: 10.1097/00007632-199106001-00025

17. Ogiela DM, Chan DP.Ventral derotation spondylodesis.A review of 22 cases. Spine (Phila Pa 1976). 1986 Jan-Feb;11(1):18-22. DOI: 10.1097/00007632-198601000-00005

18. Möller H1, Hedlund R. Instrumented and noninstrumented posterolateral fusion in adult spondylolisthesis-a prospective randomized study: part 2. Spine (Phila Pa 1976). $2000 \mathrm{Jul}$ 1;25(13):1716-21. DOI: 10.1097/00007632-200007010-00017

19. Cha CW1, Deible C, Muzzonigro T, Lopez-Plaza I, Vogt M, Kang JD. Allogeneic transfusion requirements after autologous donations in posterior lumbar surgeries. Spine, 01 Jan 2002, 27(1):99104. DOI: 10.1097/00007632-200201010-00023

20. Gurr KR1, McAfee PC. Cotrel-Dubousset instrumentation in adults.A preliminary reportSpine (Phila Pa 1976). 1988 May;13(5):510-20. DOI: 10.1097/00007632-198805000-00014

21. Hur SR, Huizenga BA, Major M. Acute normovolemic hemodilution combined with hypotensive anesthesia and other techniques to avoid homologous transfusion in spinal fusion surgeryspine (Phila Pa 1976). 1992 Aug;17(8):867-73. DOI: 10.1097/00007632-199208000-00002

22. Winter RB, Lonstein JE. Adult idiopathic scoliosis treated with Luque or Harrington rods and sublaminar wiring.J Bone Joint Surg Am. 1989 Oct;71(9):1308-13. PMID: 2793882

23. Toyota S, Amaki Y. Hemodynamic evaluation of the prone position by transesophageal echocardiography. J Clin Anesth 1998; 9: 32-5. DOI: 10.1016/s0952-8180(97)00216-x

24. Soliman DE, Maslow AD, Bokesch PM, et al. Transesophageal echocardiography during scoliosis repair: comparison with CVP monitoring. Can J Anaesth 1998; 45: 925-32. DOI: 10.1007/BF03012298

25. Yaster M, Simmons RS, Tolo VT, et al. A comparison of nitroglycerin and nitroprusside for inducing hypotension in children: a double blind study. Anesthesiology 1986; 65: 175-9. DOI: 10.1097/00000542-198608000-00008 
26. Tobias JD. Fenoldopam for controlled hypotension during spinal fusion in children and adolescents. Paediatr Anaesth 2000; 9: 261-6. DOI: 10.1046/j.1460-9592.2000.00502.x

27. Ponder PC, Dickson JH, Harrington PR, Erwin WD. Results of Harrington instrumentation and fusion in the adult idiopathic scoliosis patient. J Bone Joint Surg Am. 1975 Sep;57(6):797-801. PMID: 1158918

28. Kang WS, Oh CS, Kwon WK, Rhee KY, Lee YG, Kim TH, Lee SH, Kim SH. Effect of Mechanical Ventilation Mode Type on Intra- and Postoperative Blood Loss in Patients Undergoing Posterior Lumbar Interbody Fusion Surgery: A Randomized Controlled Trial. Anesthesiology. 2016 Jul;125(1):115-23. DOI: 10.1097/ALN.0000000000001131.

29. Le Guen M, Paternot A, Declerck A, Feliot E, Gayat E, Gaillard S, Fischler M. Impact of the modality of mechanical ventilation on bleeding during pituitary surgery: A single blinded randomized trial. Medicine (Baltimore). 2019 Sep;98(38): e17254. DOI: 10.1097/MD.0000000000017254.

\section{Tables}

Table 1: Demographic and bleeding

\begin{tabular}{|lllll|}
\hline & VCV group & PCV group & p-value \\
Male & $15(38.5 \%)$ & $16(41 \%)$ & $\mathbf{0 . 8 2}$ \\
Female & $24(61.5 \%)$ & $23(59 \%)$ & \\
Age (year) & $42.41 \pm 10.45$ & $43.77 \pm 11.38$ & 0.53 \\
Height(meter) & $1.65 \pm .9$ & $1.66 \pm .1$ & $\mathbf{0 . 5 4}$ \\
Weight(kg) & $76.11 \pm 11.47$ & $78.77 \pm 19.71$ & $\mathbf{0 . 1 3}$ \\
BMI & $27.92 \pm 4.89$ & $28.42 \pm 7.10$ & $\mathbf{0 . 9 3}$ \\
\hline
\end{tabular}

* Independent T test

Table 2: Mean bleeding volume in the studied groups

\begin{tabular}{|llll|}
\hline Group & Mean & SD & P value* \\
VCV & 465.26 & 33.81 & \multirow{2}{*}{0.67} \\
PCV & 431.28 & 36.10 & \\
\hline
\end{tabular}

* Independent T test

Table 3: Frequency of injectable pack cell in the studied groups 


\begin{tabular}{|c|c|c|c|c|c|}
\hline Group & 0 & 1 & 2 & Sum & $P$ value \\
\hline VCV & $29(74.4 \%)$ & $3(7.7 \%)$ & $7(17.9 \%)$ & $39(100 \%)$ & \multirow[t]{3}{*}{$1^{*}$} \\
\hline PCV & $30(75 \%)$ & $3(10 \%)$ & $6(15 \%)$ & $39(100 \%)$ & \\
\hline Sum & $59(74.7 \%)$ & $6(8.9 \%)$ & $13(16.5 \%)$ & $78(100 \%)$ & \\
\hline
\end{tabular}

* Fisher's Exact test

Table 4: Satisfaction surgeon from the surgical field

\begin{tabular}{|llll|}
\hline Surgeon satisfaction & VCV Group & PCV Group & Sum \\
\hline Good & $29(74.36 \%)$ & $32(82.1 \%)$ & $\mathbf{6 1 ( 7 8 . 2 \% )}$ \\
\hline Moderate & $9(23.8 \%)$ & $7(17.9 \%)$ & $\mathbf{1 6 ( 2 0 . 5 \% )}$ \\
\hline weak & $1(2.56 \%)$ & 0 & $\mathbf{1 ( 1 . 3 \% )}$ \\
\hline Sum & $39(100 \%)$ & $39(100 \%)$ & $\mathbf{7 8 ( 1 0 0 \% )}$ \\
\hline P Value & ${ }^{*} 58 / 0$ & & \\
\hline
\end{tabular}

Table 5: Frequency of need to use antihypertensive drugs in the studied groups

\begin{tabular}{|llll|}
\hline Group & $\begin{array}{l}\text { Need for Blood pressure-lowering } \\
\text { drugs }\end{array}$ & $\begin{array}{l}\text { No Need for Blood pressure-lowering } \\
\text { drugs }\end{array}$ & Sum \\
\hline VCV & $4(10.3 \%)$ & $35(89.7 \%)$ & $39(100 \%)$ \\
\hline PCV & $2(5.1 \%)$ & $37(94.9 \%)$ & $39(100 \%)$ \\
\hline Sum & $6(7.7 \%)$ & $72(92.3 \%)$ & $78(100 \%)$ \\
\hline $\begin{array}{l}\text { P } \\
\text { Value }\end{array}$ & ${ }^{*} 22 / 0$ & & \\
\hline
\end{tabular}

* Chi Square

Table 6: Mean hemoglobin of patients before and after surgery in the study groups 


\begin{tabular}{|lllll|}
\hline Time & Group & Mean & SD & P value $^{*}$ \\
\hline Before surgery & VCV & 13.39 & 1.47 & 0.772 \\
\cline { 2 - 4 } & PCV & 13.48 & 1.41 & \\
\hline \multirow{2}{*}{ After surgery } & VCV & 11.92 & 1.43 & 0.775 \\
\cline { 2 - 4 } & PCV & 12.01 & 1.41 & \\
\hline
\end{tabular}

* Independent T test 